\title{
Valores Energéticos de Subprodutos de Origem Animal para Aves
}

\author{
Ricardo Vianna Nunes ${ }^{1}$, Paulo César Pozza1, Christiane Garcia Vilela Nunes², Evandro \\ Campestrini ${ }^{3}$, Rodrigo Kühl ${ }^{4}$, Leonardo D. da Rocha ${ }^{4}$, Fernando Guilherme Perazzo Costa ${ }^{5}$
}

\begin{abstract}
RESUMO - Foram determinados os valores de energia metabolizável aparente (EMA) e energia metabolizável aparente corrigida pelo balanço de nitrogênio $\left(\right.$ EMA $_{n}$ ) e os coeficientes de metabolizabilidade aparente (CMA) e aparente corrigida pelo balanço de nitrogênio $\left(\mathrm{CMA}_{\mathrm{n}}\right)$ de cinco alimentos. Cento e vinte pintos de corte com 21 dias de idade foram distribuídos aleatoriamente em seis tratamentos (uma ração-referência e cinco rações-teste) e quatro repetições de cinco aves. Os alimentos avaliados foram: resíduo de incubatório (RI), farinha de penas (FP), farinha de vísceras de aves (FVA) e duas farinhas de carne e ossos (FCO 1 e FCO 2). Os alimentos substituíram

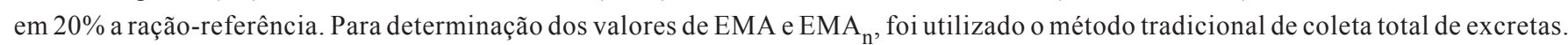
Os valores de EMA, expressos em kcal/kg de matéria natural (MN), para os alimentos RI, FP, FVA, FCO 1 e FCO 2, foram de 1.495, 2.774, 2.676, 2.537 e 1.652 e os de EMA $_{\mathrm{n}}$, de 1.301, 2.758, 2.384, 2.307 e 1.488, respectivamente. De acordo com os valores de EMA, EMA $_{\mathrm{n}}$ e energia bruta (EB), foram calculados os CMA e o CMA $\mathrm{n}$ para os alimentos RI, FP, FVA, FCO 1 e FCO 2, que foram, respectivamente, de 60,$09 ; 55,49 ; 69,31 ; 67,71$ e 51,14 , para o CMA, e de 52,26; 55,18; 61,75; 60,85 e 46,07, para o CMA .
\end{abstract}

Palavras-chave: resíduo de incubatório, farinha de penas, farinha de vísceras de aves, farinha de carne e ossos

\section{Energy Values of Animal By-Products for Poultry}

\begin{abstract}
The apparent metabolizable energy (AME), nitrogen corrected apparent metabolizable ( MME $_{\mathrm{n}}$ ), apparent metabolizability coefficient (AMC) and nitrogen corrected apparent metabolizability coefficient $\left(\mathrm{AMC}_{\mathrm{n}}\right)$ of five feedstuffs were determined. The feedstuffs investigated were: hatchery by-product meal (HM), feather meal (FM), poultry viscera meal (PVM) and two meat and bone meal (MBM 1 and MBM 2) of different origin. The values of $A M E$ and $\mathrm{AME}_{\mathrm{n}}$ were determined by the total excreta collection method. One hundred and twenty broiler chicks at 21 days old were randomly allotted to six treatments (one basal reference diet and five test diets), with four replications with five birds per experimental unit. The feedstuffs replaced $20 \%$ reference diet. The AME values expressed in $\mathrm{kcal} / \mathrm{kg}$ as-fed basis for feedstuffs HM, FM, PVM, MBM 1 and MBM 2 were: 1.495, 2.774, 2.676, 2.567 and 1.652 and the $\mathrm{AME}_{\mathrm{n}}$ values were: 1.301, 2.758, 2.384, 2.307 and 1.488, respectively. According to $\mathrm{AME}, \mathrm{AME}_{\mathrm{n}}$ and gross energy (GE) values, the $\mathrm{AMC}$ and $\mathrm{AMC}_{\mathrm{n}}$ were calculated for $\mathrm{xHM}, \mathrm{FM}, \mathrm{PVM}, \mathrm{MBM} 1$ and MBM $2(8,79 \%)$, that showed the respective values of 0.09 , 55.49, 69.31, 67.71 and 51.14 for $\mathrm{AMC}$ and 52.26, 55.18, 61.75, 60.85 and 46.07 for $\mathrm{AMC}_{\mathrm{n}}$.
\end{abstract}

Key Words: hatchery by-product meal, feather meal, poultry viscera meal, meat and bone meal

\section{Introdução}

A avicultura industrial é uma das atividades agrícolas mais desenvolvidas no mundo. Impulsionada sobretudo pela necessidade de utilização de proteína de origem animal na dieta humana, a produção avícola no Brasil representa uma das mais importantes cadeias produtivas (Figueiredo, 2001).

Em 2002, a produção brasileira de carne de frango foi de 7,449 milhões de toneladas, o que representa um crescimento de 13,5\% em relação a 2001. Em 2003, foram produzidos 8,045 milhões de toneladas e, para 2004, há uma estimativa de que a produção brasileira atinja 8,450 milhões de toneladas (Aves \& Ovos,
2003). Segundo dados do USDA, entre os países que se destacam no setor, o Brasil ocupa o terceiro lugar no mercado mundial de produção de carne de frango (Avicultura Industrial, 2003).

Para que o setor mantenha o sucesso, é preciso investir em produtividade a baixo custo. Além disso, é necessário atenção especial à questão ambiental, destacando-se a importância do aproveitamento dos resíduos da indústria avícola.

No processo de incubação, ocorrem perdas de 8 a $12 \%$ dos ovos e, no processamento do frango de corte no abatedouro, em torno de $35 \%$, gerando uma quantidade significativa de resíduos (Nunes, 1998), que, por serem poluentes e contaminarem a água, o solo e

\footnotetext{
${ }^{1}$ Professor - Curso de Zootecnia, UNIOESTE, 85960-000 - Marechal Cândido Rondon, PR (nunesrv@hotmail.com).

2 Estudante Doutorado, Departamento Zootecnia, UFV - 36571-000 - Viçosa, MG.

${ }^{3}$ Estudante de Mestrado, UEM - Maringá, PR.

4 Estudantes de Zootecnia, UNIOESTE - 85960-000 - Marechal Cândido Rondon, PR.

5 Professor - Departamento de Zootecnia, UFPB, 58397-000 - Areia, PB.
} 
o ar, tornaram-se a grande preocupação das organizações ambientais. Uma das formas de aproveitamento desses resíduos é o seu processamento, que origina subprodutos, como as farinhas de vísceras, de penas, de carne e ossos e de resíduo de incubatório, que podem ser utilizados na alimentação animal.

Os gastos com alimentação representam em torno de $70 \%$ do custo total de produção das aves, gerando a necessidade de se buscarem novas alternativas que atendam às exigências nutricionais dos animais nas diferentes fases de produção. Conhecendo os valores nutricionais dos alimentos alternativos, pode-se utilizá-los de maneira correta, reduzindo os custos das rações (Vieites, 1999).

O estudo de alimentos alternativos torna-se necessário não apenas em razão do seu efeito poluente, mas também da busca por rações economicamente viáveis e eficientes. Para seu uso correto, é importante conhecer seus valores nutricionais, e seu conteúdo relativo de energia, visto que os níveis energéticos das rações são o principal fator limitante para o ótimo desempenho das aves (Nunes, 2000; Albino, 1995). Geralmente, acredita-se que os valores de energia metabolizável são propriedades da dieta, entretanto, a EM é uma característica do animal em relação à dieta (McNab, 2000). A formulação de rações é um processo de combinação das exigências nutricionais dos animais com os valores nutricionais dos alimentos, tornando a acurácia do valor nutricional dos alimentos utilizados de extrema importância.

Alguns ingredientes são padronizados, com valores nutricionais bem estáveis, enquanto outros não são padronizados e podem apresentar grande variação, tornando indispensável a determinação de sua composição química e de seu valor nutricional (Albino \& Silva, 1996). Segundo Junqueira (1999), há grande variação entre os valores energéticos apresentados nas diversas tabelas de exigências de composição química, dificultando a comparação entre os nutrientes presentes nos alimentos. Por isso, vários estudos tem sido desenvolvidos visando atualizar os valores nutricionais dos alimentos comumente utilizados na alimentação animal e conhecer o valor nutricional de novos ingredientes, tornando as tabelas mais completas e com valores mais precisos.

Este trabalho foi realizado para determinar os valores de energia metabolizável aparente (EMA) e energia metabolizável aparente corrigida pelo balanço de nitrogênio $\left(\right.$ EMA $_{n}$ ) e os coeficientes de metabolizabilidade aparente e aparente corrigida pelo balanço de nitrogênio de diferentes alimentos de origem animal.

\section{Material e Métodos}

O ensaio biológico foi conduzido no Setor de Avicultura do Departamento de Zootecnia (DZO) da Universidade Federal de Viçosa (UFV), utilizando-se o método tradicional de coleta total de excretas.

As temperaturas médias máxima e mínima e seus respectivos desvios-padrão no interior da sala de estudos de metabolismo, durante a fase experimental, foram de $26,8 \pm 3,77$ e $19,6 \pm 1,52^{\circ} \mathrm{C}$, respectivamente, às $8 \mathrm{~h}$, e de $26,6 \pm 3,44$ e $21,2 \pm 0,84^{\circ} \mathrm{C}$, respectivamente, às $17 \mathrm{~h}$.

Os alimentos estudados foram compostos por uma amostra de resíduo de incubatório (RI), uma de farinha de penas (FP), uma de farinha de vísceras de aves (FVA) e duas amostras de farinha de carne e ossos de diferentes procedências.

Para determinação dos valores de EMA e EMA ${ }_{n}$, foram utilizados 120 pintos de corte machos da linhagem UFV, com 21 dias de idade e peso médio de $550 \mathrm{~g}$. O ensaio biológico foi constituído por cinco rações-teste e uma ração-referência (Tabela 1), calculada segundo recomendações de Rostagno et al. (2000), de modo que cada alimento avaliado substituiu em $20 \%$ a ração-referência.

Foi adotado delineamento experimental inteiramente casualizado, com seis tratamentos, quatro repetições e cinco aves por unidade experimental. Até o $21^{0}$ dia de idade, as aves receberam ração inicial para frangos de corte e, a partir desta idade, foram transferidas para baterias de estrutura metálica com compartimentos distribuídos em dois andares, onde permaneceram durante 10 dias (cinco de adaptação e cinco para a coleta total das excretas), recebendo água e ração à vontade. As coletas foram realizadas duas vezes ao dia, às 8 e $17 \mathrm{~h}$. Para evitar perdas, utilizaram-se bandejas cobertas com plástico, colocadas sob cada compartimento das gaiolas. Ao término do período experimental, foi determinada a quantidade de ração consumida por unidade experimental, durante os cinco dias de coleta.

As excretas foram acondicionadas em sacos plásticos, devidamente identificados, e armazenadas em freezer até o final do período experimental. Posteriormente, foram descongeladas, pesadas, homogeneizadas, 
\begin{tabular}{c} 
Tabela 1 - Composição da ração-referência, porcenta- \\
gem na matéria natural \\
Table 1 - $\begin{array}{l}\text { Composition (\%) of the reference diet, } \\
\text { as-fed basis }\end{array}$ \\
\hline
\end{tabular}

Ingrediente

$(\%)$

Ingredient

Milho (Corn)

70,65

Farelo de soja (Soybean meal)

23,91

Óleo vegetal (Vegetable oil)

1,50

Calcário (Limestone)

0,96

Fosfato bicálcico (Dicalcium phosphate)

1,64

Sal (Salt)

0,39

L-lisina HCL (L-lysine) $(78,4 \%)$

0,30

DL-metionina (DL-methionine) (99\%)

0,26

Cloreto de colina (Choline chloride) $(60 \%) \quad 0,06$

L-treonina (L-threonine) (98\%)

Mistura mineral ${ }^{1}$ (Mineral mix $^{1}$ )

0,04

Mistura vitamínica ${ }^{2}$ (Vitamin mix ${ }^{2}$ )

0,06

0,13

Anticoccidiano $^{3}$ (Anticoccidial)

0,06

Promotor de crescimento ${ }^{4}$ (Growth promoter) $\quad 0,02$

Antioxidante $^{5}$ (Antioxidant)

0,02

Composição calculada

Calculated composition

Energia metabolizável (cal/kg)

3086

Metabolizable energy

Proteína bruta (Crude protein) $(\%)$

Lisina digestível (Digestive lysine) (\%)

Metionina digestível (\%)

Digestible methionine

Metionina + cistina digestível (\%) $\quad 0,76$

Digestible meth + cys

Triptofano digestível (\%) $\quad 0,18$

Digestible tryptophan

Treonina digestível (\%) $\quad 0,61$

Digestible threonine

Cálcio (Calcium) (\%)

0,87

Fósforo disponível (\%)

0,41

(Available phosphorus)

0,19

${ }^{1}$ Conteúdo/kg (Content/kg): Fe, 100 g; Cu, 16 g; Mn, 150 g; Zn, $100 \mathrm{~g}$; I, 1,5 g.

${ }^{2}$ Conteúdo/kg (Content/kg): Vit. A, 10.000.000 UI; Vit. $D_{3}, 2.200 .000$ UI; Vit. E, 6.000 UI; Vit. B , 1,4 g; Vit. $B_{2}, 4,0$ g; Vit. $B_{6}, 1,8$ g; Vit.

$\mathrm{B}_{12}, 15.000 \mathrm{mcg}$; Ác. pantotênico (pantothenic acid), 8,5 g; Vit. K,

1,4 g; Ác. fólico (pholic acid), 0,4 g; Ác. nicotínico (nicotinic acid), $25,0 \mathrm{~g} ; \mathrm{Se}, 0,3 \mathrm{~g}$

${ }^{3}$ Coxistac.

${ }^{4}$ Virginiamicina (virginiamicin).

${ }^{5} \mathrm{BHT}$.

retirando-se amostras para as análises laboratoriais, realizadas após a pré-secagem em estufa ventilada a $55^{\circ} \mathrm{C}$, para cálculo dos teores de de matéria seca, de nitrogênio e de energia bruta.

As análises químicas dos alimentos foram realizadas no Laboratório de Nutrição Animal da Universidade Federal de Viçosa, determinando-se os valores de matéria seca (MS), extrato etéreo (EE), fibra bruta
$(\mathrm{FB})$, proteína bruta $(\mathrm{PB})$, energia bruta $(\mathrm{EB})$, matéria mineral $(\mathrm{MM})$, cálcio $(\mathrm{Ca})$, fósforo $(\mathrm{P})$, magnésio $(\mathrm{Mg})$, sódio $(\mathrm{Na})$ e potássio $(\mathrm{K})$, segundo metodologia descrita por Silva \& Queiroz (2002). O diâmetro geométrico médio das partículas dos alimentos (DGM) foi estimado de acordo com técnica descrita por Zanotto \& Bellaver (1996).

Os valores de energia metabolizável aparente (EMA) e aparente corrigida pelo balanço de nitrogênio $\left(\mathrm{EMA}_{\mathrm{n}}{ }^{-}\right)$foram calculados segundo equações propostas por Matterson et al. (1965). Os coeficientes de metabolizabilidade da energia bruta, em relação

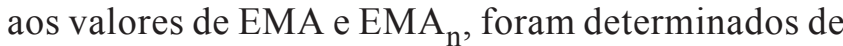
acordo com Lesson \& Summers (2001).

Como procedimento estatístico, aplicou-se o teste de Student Newman-Keuls a 5\% de probabilidade aos valores médios dos coeficientes de metabolizabilidade, utilizando-se o Sistema de Análises Estatísticas e Genéticas - SAEG (Universidade Federal de Viçosa, 1999).

\section{Resultados e Discussão}

A composição química, os valores de energia bruta e o diâmetro geométrico médio das partículas (DGM) dos alimentos encontram-se na Tabela 2 . Houve variação nos valores da composição química dos alimentos quando comparados aos da literatura (Rostagno et al., 2000; Anfar, 1985; Embrapa, 1991; Lesson \& Summers, 2001; NRC, 1994; Janssen, 1989).

Para o resíduo de incubatório, os valores de PB $(26,05 \%)$, EE (12,26\%) e MM (54,84\%) foram semelhantes aos recomendados pela Embrapa (1991). Porém, os valores obtidos para Ca e P (24,72 e 0,31\%) foram diferentes, uma vez que a Embrapa prescreve valores de até 19,05 e 0,53\%, respectivamente. Esses valores resultaram da maior ou menor inclusão de casca de ovos no processamento do resíduo, visto que a composição química do resíduo de incubatório pode variar de acordo com o tratamento a que foi submetido. Vanderpopulire (1976) relatou que trabalhos desenvolvidos com resíduos de incubatório submetidos à desidratação por calor seco favoreceram a produção de farinha com composição adequada, mas bastante variável, conforme a porcentagem de eclodibilidade do incubatório. Quando a eclodibilidade é elevada, a farinha obtida apresenta reduzido nível de proteína e alto nível de cálcio, ocorrendo o inverso quando a eclodibilidade é baixa. 
Tabela 2 - Composição química, valores de energia bruta e diâmetro geométrico médio (DGM) dos alimentos, na matéria natural

Table 2 - Chemical composition, gross energy values and mean geometric diameter (MGD) of the feeds, as-fed basis

\begin{tabular}{|c|c|c|c|c|c|c|c|c|c|c|c|c|}
\hline $\begin{array}{l}\text { Alimento } \\
\text { Feedstuff }\end{array}$ & $\begin{array}{l}\text { MS } \\
(\%) \\
D M\end{array}$ & $\begin{array}{c}\mathrm{EB} \\
(\mathrm{kcal} / \mathrm{kg}) \\
G E\end{array}$ & $\begin{array}{c}\mathrm{PB} \\
(\%) \\
C P\end{array}$ & $\begin{array}{c}\mathrm{EE} \\
(\%) \\
E E\end{array}$ & $\begin{array}{l}\text { FB } \\
(\%) \\
C F\end{array}$ & $\begin{array}{l}\text { MM } \\
(\%) \\
\text { Ash }\end{array}$ & $\begin{array}{c}\mathrm{Ca} \\
(\%)\end{array}$ & $\begin{array}{l}\mathrm{P} \\
(\%)\end{array}$ & $\begin{array}{l}\mathrm{Mg} \\
(\%)\end{array}$ & $\begin{array}{l}\mathrm{Na} \\
(\%)\end{array}$ & $\begin{array}{l}\mathrm{K} \\
(\%)\end{array}$ & $\begin{array}{l}\text { DGM } \\
(\mathrm{mm}) \\
M G D\end{array}$ \\
\hline $\begin{array}{l}\text { Resíduo incubatório } \\
\text { Hatchery by-product meal }\end{array}$ & 96,33 & 2.489 & 26,05 & 12,26 & 1,96 & 54,84 & 24,72 & 0,31 & 0,24 & 0,46 & 0,03 & 710,35 \\
\hline $\begin{array}{l}\text { Farinha de penas } \\
\text { Feather meal }\end{array}$ & 89,49 & 4.999 & 64,52 & 4,18 & 0,10 & 2,05 & 0,16 & 0,23 & 0,03 & 0,43 & 0,23 & 603,99 \\
\hline $\begin{array}{l}\text { Farinha vísceras de aves } \\
\text { Poultry viscera meal }\end{array}$ & 92,93 & 3.861 & 46,72 & 12,42 & 0,72 & 24,63 & 9,62 & 4,02 & 0,19 & 0,62 & 0,48 & 659,11 \\
\hline $\begin{array}{l}\text { Farinha de carne e ossos } 1 \\
\text { Meat and bone meal } 1\end{array}$ & 92,41 & 3.791 & 47,01 & 11,62 & 0,57 & 25,54 & 10,65 & 4,80 & 0,23 & 0,75 & 0,45 & 675,77 \\
\hline $\begin{array}{l}\text { Farinha de carne e ossos } 2 \\
\text { Meat and bone meal } 2\end{array}$ & 89,13 & 3.230 & 40,00 & 9,96 & 0,64 & 29,59 & 11,53 & 4,88 & 0,18 & 0,63 & 0,31 & 986.61 \\
\hline
\end{tabular}

${ }^{*} \mathrm{MS}=$ matéria seca; $\mathrm{EB}=$ energia bruta; $\mathrm{PB}$ = proteína bruta; $\mathrm{EE}=$ extrato etéreo; $\mathrm{FB}$ = fibra bruta; $\mathrm{MM}=$ matéria mineral ou cinza

${ }^{*} D M=$ dry matter; $G E=$ gross energy; $C P=$ crude protein; $E E=$ ether extract; $F B=$ crude fiber.

$\mathrm{O}$ valor de $\mathrm{PB}$ para a farinha de penas neste trabalho foi de $64,52 \%$, superior em $18 \%$ aos teores prescritos pela Embrapa (1991). De acordo com os padrões estabelecidos pela Anfar (1985), a farinha de penas deve conter no mínimo $80 \%$ de $\mathrm{PB}$ e no máximo $2,5 \%$ de EE, além de $1,5 \%$ de FB e $5 \%$ de MM. A PB e o EE estiveram abaixo dos padrões estabelecidos pela Anfar (1985), enquanto a FB e a MM atenderam estes padrões. Porém, valores semelhantes foram encontrados por Nascimento (2002), em que a média de PB, EE e MM de seis farinhas de penas foram de 76,$66 ; 4,42$ e $2,12 \%$, respectivamente. O conteúdo de EE da farinha de penas foi semelhante ao encontrado por Rostagno et al. (2000), mas diferiu dos valores citados pela Embrapa (1991) e pelo NRC (1994). Os valores de $\mathrm{Ca}$ e $\mathrm{P}$ foram inferiores aos recomendados por Rostagno et al. (2000), NRC (1994) e Embrapa (1991), ao passo que o valor de sódio foi superior ao citado por Rostagno et al. (2000).

Segundo a Anfar (1985), a farinha de vísceras de aves deve conter no mínimo $65 \%$ de $\mathrm{PB}$ e no máximo $1 \%$ de $\mathrm{FB}$ e $7 \%$ de $\mathrm{MM}$, podendo o conteúdo de EE variar de 8 a $12 \%$. Entretanto, apenas os valores de EE e PB da farinha de vísceras de aves atenderam a esse padrão. Valores semelhantes foram encontrados por Nascimento (2002), que, trabalhando com farinhas mistas de vísceras de aves e de suínos, obteve valores médios de $\mathrm{PB}, \mathrm{EE}$ e MM de 53,49; 13,55 e $18,77 \%$, respectivamente. Os valores de $\mathrm{Ca}(9,62 \%)$ e P $(4,02 \%)$ foram superiores aos descritos por Lesson \& Summers (2001), Rostagno et al. (2000), NRC
(1994) e Embrapa (1991). O teor de sódio da farinha de vísceras neste trabalho foi superior ao recomendado por Rostagno et al. (2000).

O fato de a farinha de vísceras ter apresentado alto conteúdo de matéria mineral, de cálcio e fósforo provavelmente contribuiu para o seu baixo conteúdo de energia bruta, uma vez que esse alimento apresentou elevado teor de extrato etéreo.

As farinhas de carne e ossos 1 e 2 apresentaram teores de PB superiores a $40 \%$ e, portanto, atenderam ao Artigo 322-D do RIISPOA e aos padrões estabelecidos pela Anfar (1985), em que as farinhas de carne e ossos devem possuir, no mínimo, $40 \%$ de proteína bruta. Porém, Rostagno et al. (2000) e Embrapa (1991) recomendam valores de 35,96 e $33,85 \%$, respectivamente, inferiores aos valores supracitados.

Os valores protéicos das farinhas de carne e ossos 1 e 2 foram semelhantes aos citados por Rostagno et al. (2000), NRC (1994) e Embrapa (1991).

Os teores de umidade das farinhas de carne e ossos analisadas foram próximos aos preconizados por Rostagno et al. (2000), NRC (1994), Embrapa (1991) e Anfar (1985). Os valores de EE (entre 10 e $12 \%$ ) foram semelhantes aos obtidos por Rostagno et al. (2000) e, portanto, atenderam aos padrões da Anfar (1985). Porém, excederam o limite determinado pelo RIISPOA, que permite, no máximo, $10 \%$ de gordura para esses alimentos.

Os teores de MM das FCO 1 e 2 (25,54 e 29,59\%) foram semelhantes aos recomendados por Rostagno 
et al. (2000). A FCO 1 apresentou valores semelhantes aos prescritos pela Embrapa (1991), enquanto a FCO 2 foi $21,76 \%$ inferior.

Os teores de fósforo das FCO 1 e 2 estão de acordo com as recomendações e a padronização da Difisa (1989), por apresentarem valores superiores a 3,8\% de fósforo. A Difisa (1989) estabelece uma relação cálcio/fósforo máxima de 2,20:1,00 e a Anfar (1985), de 2,25:1,00, conforme verificado na FCO 1. Na FCO 2, no entanto, essa relação foi de 2,40:1,00. O valor de sódio da FCO 1 foi superior ao de $0,70 \%$ proposto por Rostagno et al. (2000) para FCO com $45,37 \%$ de PB, porém, o da FCO 2 foi inferior aos $0,71 \%$ recomendados pelos autores para FCO com 40,69\% de PB.

De acordo com os valores de DGM, os alimentos testados podem ser classificados como de média granulometria. Segundo Zanotto \& Bellaver (1996), os alimentos podem ser classificados como grossos, médios e finos, quando apresentam DGM acima de $2,00 \mathrm{~mm}$; entre 2,00 e $0,60 \mathrm{~mm}$; e menor que $0,60 \mathrm{~mm}$, respectivamente. O tamanho das partículas dos alimentos destinados à fabricação de rações pode influenciar a digestibilidade dos nutrientes e, conseqüentemente, a maximização da resposta do animal, além de influenciar o rendimento da moagem (Zanotto \& Bellaver, 1996).

As diferenças na composição química dos alimentos já eram esperadas, em razão das diferentes matérias-primas utilizadas, dos fatores operacionais e dos constituintes das farinhas (Nunes, 2003; Nascimento, 2000). O tipo de processamento que cada farinha recebe pode influenciar diretamente a composição química e, portanto, a qualidade desses alimentos (Albino \& Silva, 1996). De modo geral, o conteúdo de PB das diferentes farinhas de carne e ossos é inversamente proporcional à porcentagem de MM seus níveis são os mesmos encontrados na literatura (Embrapa, 1991; Rostagno et al., 2000). Essa relação entre as proporções de proteína bruta e matéria mineral da farinha de carne e ossos é resultante da inclusão, principalmente, de ossos e tecidos tendinosos ao alimento.

Os valores de energia metabolizável aparente (EMA) e aparente corrigida pelo balanço de nitrogênio $\left(\right.$ EMA $\left._{\mathrm{n}}\right)$ e seus respectivos desvios-padrão encontram-se na Tabela 3. Houve variação dos valores

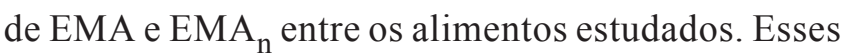
valores variaram de 1.495 a 2.774 e de 1.301 a 2.758 $\mathrm{kcal} / \mathrm{kg}$ de matéria natural $(\mathrm{MN})$, para EMA e EMA ${ }_{\mathrm{n}}$, respectivamente, e podem ter sido influenciados pela composição química e pelo DGM de cada alimento. Os valores mais baixos de EMA ${ }_{n}$, em relação à EMA, são próprios dos valores energéticos quando estes são determinados pelo método tradicional de coleta total de excretas em pintos em crescimento, o que é caracterizado pela maior retenção de nitrogênio das aves em crescimento.

$\mathrm{O}$ valor de $\mathrm{EMA}_{\mathrm{n}}$ no resíduo de incubatóriofoi inferior ao citado pela Embrapa (1991), provavelmente em razão dos subprodutos empregados na formulação do resíduo e da forma de processamento.

Os alimentos com maiores níveis de EMA e $\mathrm{EMA}_{\mathrm{n}}$ foram a farinha de penas, farinha de vísceras e farinha de carne e ossos 1, com variação de 2.774 a $2.567 \mathrm{kcal} / \mathrm{kg}$ de MN, para EMA, e de 2.758 a 2.307 $\mathrm{kcal} / \mathrm{kg}$ de $\mathrm{MN}$, para $\mathrm{EMA}_{\mathrm{n}}$.

$\mathrm{O}$ valor de $\mathrm{EMA}_{\mathrm{n}}$ para a farinha de penas foi de $2.758 \mathrm{kcal} / \mathrm{kg}$ de MN. Quando comparado aos valores descritos pelo NRC (1994) e por Janssen (1989), foi superior em 14 e $21 \%$, respectivamente, porém similar aos citados por Rostagno et al. (2000).

Para a farinha de vísceras de aves, o valor de $\mathrm{EMA}_{\mathrm{n}}$ foi de $2.384 \mathrm{kcal} / \mathrm{kg}$ de $\mathrm{MN}$, semelhante aos valores apresentados por Rostagno et al. (2000) e NRC (1994), todavia é inferior aos valores descritos pela Embrapa (1991).

Os níveis de $\mathrm{EMA}_{\mathrm{n}}$ para as farinhas de carne e ossos 1 e 2 foram de 2.307 e $1.488 \mathrm{kcal} / \mathrm{kg}$, respectivamente. Para a FCO 1, os valores foram semelhan-

Tabela 3 - Valores de energia metabolizável aparente $(E M A)$ e aparente corrigida $\left(E M A_{n}\right)$ e seus respectivos desvios-padrão (DP)*

Table 3 - Apparent metabolizable energy (AME) and the corrected apparent $\left(A M E_{n}\right)$ values and respective standard deviations $(S D)^{*}$

\begin{tabular}{|c|c|c|c|c|}
\hline $\begin{array}{l}\text { Alimento } \\
\text { Feedstuff }\end{array}$ & $\begin{array}{l}\text { EMA } \\
A M E\end{array}$ & $\begin{array}{l}\text { DP } \\
S D\end{array}$ & $\begin{array}{l}\mathrm{EMA}_{\mathrm{n}} \\
A M E n\end{array}$ & $\begin{array}{l}\mathrm{DP} \\
S D\end{array}$ \\
\hline $\begin{array}{l}\text { Resíduo incubatório } \\
\text { Hatchery by-product meal }\end{array}$ & 1.495 & \pm 117 & 1.301 & \pm 85 \\
\hline $\begin{array}{l}\text { Farinha de penas } \\
\text { Feather meal }\end{array}$ & 2.774 & \pm 196 & 2.758 & \pm 81 \\
\hline $\begin{array}{l}\text { Farinha de vísceras de aves } \\
\text { Poultry viscera meal }\end{array}$ & 2.676 & 144 & 2.384 & \pm 164 \\
\hline $\begin{array}{l}\text { Farinha de carne e ossos } 1 \\
\text { Meat and bone meal } 1\end{array}$ & 2.567 & \pm 114 & 2.307 & \pm 132 \\
\hline $\begin{array}{l}\text { Farinha de carne e ossos } 2 \\
\text { Meat and bone meal } 2\end{array}$ & 1.652 & \pm 172 & 1.488 & \pm 175 \\
\hline
\end{tabular}

* Valores expressos em $\mathrm{kcal} / \mathrm{kg}$ de matéria natural.

* Values expressed as $\mathrm{kcal} / \mathrm{kg}$, as-fed basis. 
tes aos propostos por Rostagno et al. (2000) e pelo NRC (1994), enquanto, para a FCO 2, foram 25,60\% inferiores.

Diversos fatores podem afetar os valores de energia metabolizável dos alimentos, entre eles o tipo de processamento, a idade das aves e os níveis de inclusão do ingrediente na dieta (Vieites, 1999). Entretanto, o conteúdo de PB e EE e a composição dos ácidos graxos e minerais provavelmente são os fatores que mais contribuem para as variações nos valores energéticos dos alimentos.

$\mathrm{Na}$ Tabela 4 constam os coeficientes de metabolizabilidade da energia aparente (CMA) e aparente corrigida $\left(\mathrm{CMA}_{\mathrm{n}}\right)$ dos alimentos.

Houve diferença significativa $(\mathrm{P}<0,05)$ entre os coeficientes de metabolizabilidade dos alimentos estudados. Os alimentos com maior tamanho de partícula e menor valor de energia metabolizável apresentaram os menores coeficientes de metabolizabilidade, à exceção da farinha de penas, que apresentou altos níveis de energia e baixo coeficiente de metabolizabilidade.

Os coeficientes de metabolizabilidade do resíduo de incubatório e da farinha de penas foram estatisticamente iguais $(\mathrm{P}<0,05)$, assim como a farinha de penas e a farinha de carne e ossos 2. Entretanto, numericamente, o valor obtido no resíduo de incubatório foi superior ao da farinha de penas, que, por sua vez, foi superior ao da farinha de carne e ossos 2.

O pior aproveitamento da energia foi verificado na farinha de carne e ossos $2(51,14 \%)$ e foi inferior ao da farinha de carne e ossos $1(67,71 \%)$. Esse resultado pode ser atribuído ao valor de DGM, que foi numericamente superior ao das demais farinhas. Vieites (1999), trabalhando com farinha de carne e ossos, encontrou valores de EMA e EMA $\mathrm{n}_{\mathrm{n}}$ abaixo dos prescritos nas tabelas nacionais e estrangeiras. Valores similares foram verificados por Martosiswoyo \& Jensen (1988), Brugalli (1996) e Azevedo (1997), que constataram que os valores de energia metabolizável diminuíram à medida que se aumentaram os níveis de inclusão nas rações e que, possivelmente, a inclusão de $20 \%$ de farinha de carne e ossos nas rações acarretou excesso de íons cálcio, magnésio, sódio, entre outros, no lúmen intestinal das aves, resultando em saponificação das gorduras presentes na farinha de carne e ossos, reduzindo sua utilização pelas aves. Isso também pode ter ocorrido com o resíduo de incubatório, visto que os níveis de matéria mineral e cálcio são elevados nesse alimento.
Tabela 4 - Coeficientes de metabolizabilidade aparente (CMA) e aparente corrigida $\left(\mathrm{CMA}_{n}\right)$ dos alimentos

Table 4 - Apparent metabolizability coefficients (AMC) and corrected apparent coefficient $\left(A M C_{n}\right)$ of feedstuff

\begin{tabular}{lcc}
\hline $\begin{array}{l}\text { Alimento } \\
\text { Feedstuff }\end{array}$ & $\begin{array}{c}\text { CMA } \\
A M C\end{array}$ & $\begin{array}{c}\text { CMA }_{\mathrm{n}} \\
A M C_{n}\end{array}$ \\
\hline $\begin{array}{l}\text { Residuo incubatório } \\
\text { Hatchery by-product meal }\end{array}$ & $60,09 \mathrm{~b}$ & $52,26 \mathrm{~b}$ \\
$\begin{array}{l}\text { Farinha de pena } \\
\text { Feather meal }\end{array}$ & $55,49 \mathrm{bc}$ & $55,18 \mathrm{~b}$ \\
$\begin{array}{l}\text { Farinha de vísceras de aves } \\
\text { Poultry viscera meal }\end{array}$ & $69,31 \mathrm{a}$ & $61,75 \mathrm{a}$ \\
$\begin{array}{l}\text { Farinha de carne e ossos 1 } \\
\text { Meat and bone meal 1 }\end{array}$ & $67,71 \mathrm{a}$ & $60,85 \mathrm{a}$ \\
$\begin{array}{l}\text { Farinha de carne e ossos 2 } \\
\text { Meat and bone meal 2 }\end{array}$ & $51,14 \mathrm{c}$ & $46,07 \mathrm{c}$ \\
$\mathrm{CV}$ & 6,37 & 6,39 \\
\hline
\end{tabular}

a,b,c Médias de cada variável seguidas de letras distintas nas colunas diferem $(p<0,05)$ pelo teste e SNK.

$a, b, c$ Means followed by different letters in the collumns differ $(p<0.05)$ by SNK test.

A farinha de penas apresentou baixo coeficiente de metabolizabilidade, provavelmente em razão do baixo valor de extrato etéreo dessa farinha. Nunes (2003), trabalhando com alimentos de origem animal, observou que as aves alimentadas com farinhas de penas apresentaram os menores valores de aproveitamento da energia bruta dos alimentos na forma de energia metabolizável e atribuiu esse resultado ao menor conteúdo de extrato etéreo e aos valores de DGM.

Segundo Brugalli (1996), as diferenças nos valores de DGM podem ocasionar diferenças nos valores energéticos, pois, quanto maior a partícula, menor a superfície de exposição à ação das enzimas digestivas e maior a taxa de passagem pelo trato gastrointestinal. O tempo de passagem do bolo alimentar pelo trato digestivo das aves é relativamente curto e, portanto, a redução do tamanho das partículas pode contribuir substancialmente para melhor digestão e absorção dos nutrientes.

A farinha de vísceras de aves e a farinha de carne e ossos 1 apresentaram os melhores coeficientes de metabolizabilidade e foram consideradas estatisticamente iguais, embora, numericamente, a farinha de vísceras proporcione melhor aproveitamento da energia bruta em forma de energia metabolizável. Observou-se que estas duas farinhas apresentaram baixo valor de DGM, o que pode ter contribuído para o melhor aproveitamento desta energia. 
Nunes (2003) observou que os melhores coeficientes de metabolizabilidade de produtos de origem animal foram obtidos com farinhas de vísceras de aves, todavia, os resultados reportados por esse autor foram 4,21\% inferiores aos obtidos neste trabalho.

As grandes variações encontradas nos coeficientes de metabolizabilidade dos alimentos estudados podem ainda ser explicadas pelo fato de os alimentos sofrerem processamentos diferentes, resultando em matérias-primas de diferentes qualidades (Nunes, 2003).

Segundo Butolo (2002), a temperatura utilizada no processamento das farinhas de origem animal, necessária para a eliminação dos agentes patogênicos e a quebra das ligações entre os aminoácidos que formam a proteína das penas, no caso a queratina, geralmente é elevada e proporciona reações entre os nutrientes, formando complexos ou provocando a desnaturação protéica, o que torna esses nutrientes indigestíveis, ocasionando redução no valor energético dos alimentos, o que foi facilmente comprovado pelos coeficientes de metabolizabilidade verificados neste trabalho.

\section{Conclusões}

Os valores de EMA para o resíduo de incubatório, farinha de penas, a farinha de vísceras de aves, a farinha de carne e ossos 1 e a farinha de carne e ossos 2 foram de $1.495,2.774,2.676,2.567$ e $1.652 \mathrm{kcal} / \mathrm{kg}$, respectivamente, e os de $\mathrm{EMA}_{\mathrm{n}}$, de 1.301, 2.758, 2.384, 2.307 e $1.488 \mathrm{kcal} / \mathrm{kg}$, respectivamente.

Os coeficientes de metabolizabilidade aparente para os alimentos resíduo de incubatório, farinha de penas, farinha de vísceras de aves, farinha de carne e ossos 1 e farinha de carne e ossos 2 foram de 60,09; 55,$49 ; 69,31 ; 67,71$ e $51,14 \%$, respectivamente, e os de metabolizabilidade aparente corrigida, de 52,26; 55,$18 ; 61,75 ; 60,85$ e $46,07 \%$, respectivamente.

\section{Literatura Citada}

ALBINO, L.F.T. Metodologia da determinação da disponibilidade de energia em alimentos para aves e suínos. In: SIMPÓSIO LATINO-AMERICANO DE NUTRIÇÃO DE SUÍNOS E AVES, 1995, Campinas. Anais... Campinas, 1995. 166p.

ALBINO, L.F.T.; SILVA, M.A. Valores nutritivos de alimentos para aves e suínos determinados no Brasil. In: SIMPÓSIO INTERNACIONAL SOBRE EXIGÊNCIAS NUTRICIONAIS DE AVES E SUÍNOS, 1996, Viçosa, MG. Anais... Viçosa, MG: Universidade Federal de Viçosa, 1996. p.303-318.

ASSOCIAÇÃO NACIONAL DOS FABRICANTES DE RAÇÕES - Anfar. Matérias-primas para alimentação animal - padrão. 4.ed. 1985. 65p.
AVES e OVOS. Produção brasileira de frango de corte. www.aveseovos.com.br. Acesso em: 15/11/2003.

AVICULTURA INDUSTRIAL. Produção mundial de carne de frango. www.aviculturaindustrial.com.br. Acesso em: $15 / 11 / 2003$.

AZEVEDO, D.M.S. Fatores que influenciam os valores de energia metabolizável da farinha de carne e ossos para aves. Viçosa, MG: Universidade Federal de Viçosa, 1997. 68p. Dissertação (Mestrado em Zootecnia) - Universidade Federal de Viçosa, 1997.

BRUGALLI, I. Efeito da granulometria na biodisponibilidade de fósforo e nos valores energéticos da farinha de carne e ossos e exigência nutricional de fósforo para pintos de corte. Viçosa, MG: Universidade Federal de Viçosa, 1996. 83p. Dissertação (Mestrado em Zootecnia) - Universidade Federal de Viçosa, 1996.

BUTOLO, J.E. Qualidade de ingredientes na alimentação animal. Campinas: 2002. 430p.

DIVISÃO DE FISCALIZAÇÃO DE ALIMENTOS PARA ANIMAIS - Difisa. Padrões oficiais de matérias-primas destinadas à alimentação animal. Brasília, 1989. 40p.

EMPRESA BRASILEIRA DE PESQUISA AGROPECUÁRIA EMBRAPA - CNPSA. Tabelas de composição química e valores energéticos de alimentos para suínos e aves. 3.ed. Concórdia: CNPSA, 1991. 97p. (Documento, 19)

FIGUEIREDO, E.A.P. Como está a avicultura brasileira. Revista Brasileira de Agropecuária, ano II no 13. 2001. p.12-16.

JANSSEN, W.M.A. European table of energy values for poultry feedstuffs. 3 .ed. $1989.84 \mathrm{p}$.

JUNQUEIRA, O.M.; ARAÚJO, L.F. Energia para Frango de Corte. In: SIMPÓSIO INTERNACIONAL SOBRE NUTRIÇÃO DE AVES, 1999, Campinas. Anais... Campinas: 1999. p.41-52.

LESSON, S.; SUMMERS, J.D. Nutrition of the chicken. 4.ed. Guelph: University Books, 2001. 591p.

MARTOSISWOYO, A.W.; JENSEN, L.S. Available energy in meat and bone meal as measured by different methods. Poultry Science, v.67, p.280-293, Feb.1988.

MATTERSON, L.D.; POTTER, L.M.; STUTZ, M.W. et al. The metabolizable energy of feed ingredients for chickens. University of Connecticut Storrs. Agric. Exp Stat., Research Report 7, 1965.

McNAB, J.M. Rapid metabolizable energy assays. In: D’MELLO, J.P.F. (Ed.) Farm animal metabolism and nutrition critical review. London: British Library, 2000. 438p.

NASCIMENTO, A.H. Determinação do valor nutritivo da farinha de vísceras e da farinha de penas para aves, utilizando diferentes metodologias. Viçosa, MG: Universidade Federal de Viçosa, 2000. 113p. Tese (Doutorado em Zootecnia) - Universidade Federal de Viçosa, 2000.

NASCIMENTO, A.H.; GOMES, P.C.; ALBINO, L.F.T. Composição química e valores de energia metabolizável das farinhas de penas e vísceras determinados por diferentes metodologias para aves. Revista Brasileira de Zootecnia, v.31, n.3, p.1409-1417, 2002.

NATIONAL RESEARCH COUNCIL - NRC. Nutrients requirements of poultry. 9.ed. Washington, D.C.: National Academic of Science, 1994. 155p.

NUNES, R.V. Aproveitamento de Resíduos de Incubatório e de Granja. CONGRESSO NACIONAL DOS ESTUDANTES DE ZOOTECNIA, 1998, Viçosa, MG. Anais... Viçosa, MG: Universidade Federal de Viçosa, 1998. p.295-314. 
NUNES, R.V. Valores energéticos e aminoácidos digestíveis do grão de trigo e seus subprodutos para aves. Viçosa, MG: Universidade Federal de Viçosa, 2000. 78p. Dissertação (Mestrado em Zootecnia) - Universidade Federal de Viçosa, 2000.

NUNES, R.V. Digestibilidade de nutrientes e valores energéticos de alguns alimentos para aves. Viçosa, MG: Universidade Federal de Viçosa, 2003. 103p. Dissertação (Doutorado em Zootecnia) - Universidade Federal de Viçosa, 2003.

ROSTAGNO, H.S. Tabelas brasileiras para aves e suínos: Composição dos alimentos e exigências nutricionais. Viçosa, Universidade Federal de Viçosa, 2000. 141p.

SILVA, D.J.; QUEIROZ, A.C. Análises de alimentos: métodos químicos e biológicos. Viçosa, MG: Universidade Federal de Viçosa, 2002. 235p.

UNIVERSIDADE FEDERAL DE VIÇOSA - UFV. Manual de utilização do programa SAEG - Sistema de análise estatística e genética. Viçosa, MG: Universidade Federal de Viçosa, 1999. 59p.
VANDERPOPULIERE, J.M. Convert hatchery wastes into feedstuffs. Poultry Digest, n.6, p.247-248, 1976.

VIEITES, F.M. Valores energéticos e de aminoácidos digestíveis de farinhas de carne e ossos para aves. Viçosa, MG: Universidade Federal de Viçosa, 1999. 75p. Dissertação (Mestrado em Zootecnia) - Universidade Federal de Viçosa, 1999.

ZANOTTO, D.L.; BELLAVER, C. Método de determinação da granulometria de ingredientes para uso em rações de suínos e aves. Concórdia: EMBRAPA suínos e aves, 1996. p.1-5. (Comunicado técnico)

Recebido em: 20/07/04

Aceito em: 22/04/05 